\title{
Cocaine Cues and Dopamine in Dorsal Striatum: Mechanism of Craving in Cocaine Addiction
}

\author{
Nora D. Volkow, ${ }^{1}$ Gene-Jack Wang, ${ }^{2}$ Frank Telang, ${ }^{1}$ Joanna S. Fowler, ${ }^{3}$ Jean Logan, ${ }^{3}$ Anna-Rose Childress, ${ }^{4}$ \\ Millard Jayne, ${ }^{1}$ Yeming Ma, ${ }^{1}$ and Christopher Wong ${ }^{3}$ \\ ${ }^{1}$ National Institute on Alcohol Abuse and Alcoholism, Bethesda Maryland 20892, ${ }^{2}$ Medical Department and ${ }^{3}$ Department of Chemistry, Brookhaven \\ National Laboratory, Upton, New York 11973, and ${ }^{4}$ Department of Psychiatry, University of Pennsylvania School of Medicine, Philadelphia, Pennsylvania \\ 19104
}

The ability of drugs of abuse to increase dopamine in nucleus accumbens underlies their reinforcing effects. However, preclinical studies have shown that with repeated drug exposure neutral stimuli paired with the drug (conditioned stimuli) start to increase dopamine by themselves, which is an effect that could underlie drug-seeking behavior. Here we test whether dopamine increases occur to conditioned stimuli in human subjects addicted to cocaine and whether this is associated with drug craving. We tested eighteen cocaine-addicted subjects using positron emission tomography and $\left[{ }^{11} \mathrm{C}\right]$ raclopride (dopamine $\mathrm{D}_{2}$ receptor radioligand sensitive to competition with endogenous dopamine). We measured changes in dopamine by comparing the specific binding of $\left[{ }^{11} \mathrm{C}\right]$ raclopride when subjects watched a neutral video (nature scenes) versus when they watched a cocaine-cue video (scenes of subjects smoking cocaine). The specific binding of $\left[{ }^{11} \mathrm{C}\right]$ raclopride in dorsal (caudate and putamen) but not in ventral striatum (in which nucleus accumbens is located) was significantly reduced in the cocaine-cue condition and the magnitude of this reduction correlated with self-reports of craving. Moreover, subjects with the highest scores on measures of withdrawal symptoms and of addiction severity that have been shown to predict treatment outcomes, had the largest dopamine changes in dorsal striatum. This provides evidence that dopamine in the dorsal striatum (region implicated in habit learning and in action initiation) is involved with craving and is a fundamental component of addiction. Because craving is a key contributor to relapse, strategies aimed at inhibiting dopamine increases from conditioned responses are likely to be therapeutically beneficial in cocaine addiction.

Key words: imaging; raclopride; addiction; caudate; putamen; conditioned responses; $\mathrm{D}_{2}$ receptors

\section{Introduction}

Drugs of abuse increase dopamine (DA) in the nucleus accumbens (NAc), which is an effect that is believed to underlie their reinforcing effects (Di Chiara and Imperato, 1988; Koob and Bloom, 1988). However, this acute effect does not explain the intense desire for the drug and the compulsive use that occurs when addicted subjects are exposed to drug cues such as places where they have taken the drug, people with whom previous drug use occurred, and paraphernalia used to administer the drug. Cue-elicited craving is critical in the cycle of relapse in addiction (O'Brien et al., 1998). However, after more than a decade of imaging studies in cue-elicited craving, its underlying brain neurochemistry is still unknown (Childress et al., 2002). Because DA is a neurotransmitter involved with reward and with prediction of reward (Wise and Rompre, 1989; Schultz et al., 1997), DA

Received April 10, 2006; revised May 8, 2006; accepted May 14, 2006.

This work was supported by the National Institutes of Health Intramural Research Program (National Institute on Alcohol Abuse and Alcoholism), by United States Department of Energy Grant DE-AC01-76CH00016, and by National Institute on Drug Abuse Grant DA06278-15. We thank David Schlyer, David Alexoff, Paul Vaska, Colleen Shea, Youwen Xu, Pauline Carter, Kith Pradhan, Karen Apelskog, Cheryl Kassed, and Jim Swanson for their contributions.

Correspondence should be addressed to Dr. Nora D Volkow, National Institute on Drug Abuse, 6001 Executive Boulevard, Room 5274, Bethesda, MD 20892. E-mail: nvolkow@nida.nih.gov.

D0I:10.1523/JNEUROSCI.1544-06.2006

Copyright $\odot 2006$ Society for Neuroscience $\quad$ 0270-6474/06/266583-06\$15.00/0 release by drug cues is a strong candidate substrate for cueelicited craving. Studies in laboratory animals support this hypothesis: when neutral stimuli are paired with a rewarding drug they will, with repeated associations, acquire the ability to increase DA in NAc and in dorsal striatum (becoming conditioned cues), and these neurochemical responses are associated with drug-seeking behavior in rodents (Di Ciano and Everitt, 2004; Kiyatkin and Stein, 1996; Phillips et al., 2003; Vanderschuren et al., 2005; Weiss et al., 2000). The extent to which conditioned stimuli can lead to DA increases in the brain and correlated increases in subjective experiences of drug craving have not been investigated in human subjects. Imaging technologies now enable us to test whether these findings from preclinical studies translate into the experience of human drug-addicted subjects when exposed to drug cues.

Here we investigate the hypothesis that increases in DA underlie the craving experienced by addicted subjects when exposed to drug-related cues. We hypothesized that cocaine cues would increase extracellular DA in striatum in proportion to the increases in cocaine craving and that subjects with more severe addiction would have larger DA increases in response to conditioned stimuli than subjects with less severe addiction. To test this hypothesis, we studied 18 cocaine-addicted subjects with positron emission tomography $(\mathrm{PET})$ and $\left[{ }^{11} \mathrm{C}\right]$ raclopride, a DA 
$\mathrm{D}_{2}$ receptor ligand sensitive to competition with endogenous DA (Volkow et al., 1994). Subjects were tested on 2 separate days under two counterbalanced conditions: during presentation of a neutral video (natural scenery) and during presentation of a cocaine-cue video (scenes showing preparation for and simulated smoking of crack cocaine) (Childress et al., 1999). [ $\left.{ }^{11} \mathrm{C}\right]$ raclopride binding is highly reproducible (Volkow et al., 1993), and it has been shown that differences in specific binding between two conditions predominantly reflect drug-induced or behavioralinduced changes in extracellular DA (Breier et al., 1997).

\section{Materials and Methods}

Subjects. Eighteen active cocaine-addicted subjects who responded to an advertisement were studied. Subjects fulfilled DSM-IV (Diagnostic and Statistical Manual of Mental Disorders, Fourth Edition) criteria for cocaine dependence and were active users for at least the previous 6 months (free-base or crack, at least "four grams" a week). Exclusion criteria included current or past psychiatric disease other than cocaine dependence; past or present history of neurological, cardiovascular, or endocrinological disease; history of head trauma with loss of consciousness $>30 \mathrm{~min}$; and current medical illness and drug dependence other than cocaine or nicotine. Table 1 provides demographic and clinical information on the subjects. Written informed consent was obtained in all subjects.

Behavioral scales. To assess cocaine craving, we used a brief version of the Cocaine Craving Questionnaire (CCQ) (Tiffany et al., 1993), which evaluates current cocaine craving (desire to use, intention and planning to use, anticipation of positive outcome, anticipation of relief from withdrawal or distressing symptoms, and lack of control over drug use) on a seven-point visual analog scale. The average score was used as measure of cocaine craving. The CCQ was obtained before and at the end of the video.

To assess severity of cocaine addiction we used the Addiction Severity Index (ASI) (McLellan et al., 1992) and the Cocaine Selective Severity Assessment Scale (CSSA) (Kampman et al., 1998). The ASI evaluates severity across seven domains (drug, alcohol, psychiatric, family, legal, medical, and employment) and was obtained at the initial interview. The average interviewer's rating on these seven domains was used as a measure of addiction severity. The CSSA measures 18 symptoms of early cocaine abstinence that are rated on an analog scale from 0 to 7 . The CSSA was obtained before each scan.

PET scan. We used a high resolution + tomograph (resolution $4.5 \times$ $4.5 \times 4.5 \mathrm{~mm}$ full-width half-maximum, 63 slices) with [ $\left.{ }^{11} \mathrm{C}\right]$ raclopride using methods described previously (Volkow et al., 1993). Briefly, emission scans were started immediately after injection of $4-8 \mathrm{mCi}$ (specific activity $0.5-1.5 \mathrm{Ci} / \mu \mathrm{M}$ at end of bombardment). Twenty dynamic emission scans were obtained from time of injection up to $54 \mathrm{~min}$. Arterial sampling was used to quantify total carbon-11 and unchanged $\left[{ }^{11} \mathrm{C}\right] \mathrm{ra}-$ clopride in plasma. Subjects were scanned on 2 different days with $\left[{ }^{11} \mathrm{C}\right]$ raclopride under randomly ordered conditions (1) while watching a video of nature scenes (neutral condition) and (2) while watching a video that portrayed subjects smoking cocaine (cocaine-cue condition). Videos were started 10 min before injection of $\left[{ }^{11} \mathrm{C}\right]$ raclopride and were continued for $30 \mathrm{~min}$ after radiotracer injection. The neutral video featured nonrepeating segments of nature stories, and the cocainecue video featured nonrepeating segments portraying scenes that simulated purchase, preparation, and smoking of cocaine.

Image analysis. For region identification, we summed the time frames from images taken from 10-54 min and resliced them along the intercommisural plane. Planes were added in groups of two to obtain 12 planes encompassing the caudate, putamen, ventral striatum, and the cerebellum, which were measured on four, three, one, and two planes, respectively. Right

\section{Table 1. Demographic and clinical characteristic of subjects}

\begin{tabular}{ll}
\hline Age & $43 \pm 6$ years \\
Gender & 17 males, 1 female \\
Ethnicity & 15 African Americans, 3 caucasians \\
Education & $13 \pm 2$ years of education \\
Years of cocaine use & $15 \pm 7$ years \\
Route of administration & 18 smoked cocaine \\
Dose used & $2.8 \pm 1.6 \mathrm{~g} / \mathrm{d}$ \\
Days since last cocaine use & $2 \pm 1.4 \mathrm{~d}$ (range, 1 and $6 \mathrm{~d})$ \\
Cigarette smokers & 15 current smokers \\
\hline
\end{tabular}

and left regions were averaged. These regions were projected to the dynamic scans to obtain concentrations of $\mathrm{C}-11$ versus time. These timeactivity curves for tissue concentration, along with the time-activity curves for unchanged tracer in plasma, were used to calculate the transfer constant of $\left[{ }^{11} \mathrm{C}\right]$ raclopride from plasma to brain $\left(K_{1}\right)$ and the distribution volumes (DVs), which corresponds to the equilibrium measurement of the ratio of tissue concentration to plasma concentration, in striatum and cerebellum, using a graphical analysis technique for reversible systems (Logan et al., 1990). The ratio of DV in striatum to that in cerebellum corresponds to [receptor concentration (Bmax)/affinity $(\mathrm{Kd})]+1$ and is insensitive to changes in cerebral blood flow (Logan et al., 1994). The effect of the cocaine-cue video on DA was quantified as percentage change in $\mathrm{Bmax} / \mathrm{Kd}$ with respect to the neutral video.

To corroborate the location within the striatum, in which the DA changes occurred we also analyzed the DV images using statistical parametric mapping (SPM) (Friston et al., 1995). Paired $t$ tests were performed to compare the neutral and the cocaine-cue condition $(p<0.05$ uncorrected, threshold $>100$ voxels).

Statistical analysis. Differences between conditions on the behavioral and the PET measures were evaluated with paired $t$ tests (two-tailed). Product moment correlations were used to assess the correlation between the DA changes and the behavioral measures (CCQ, ASI, and CSSA).

\section{Results}

\section{Effects of cocaine cues on $\left[{ }^{11} \mathrm{C}\right]$ raclopride measures}

Because there were no differences between left and right regions, we report the results for the average scores in the left and right striatal and cerebellar regions. The $K_{1}$ measure did not differ between conditions for any of the brain regions (Table 2). This indicates that the tracer delivery was not affected by the cocainecue condition.

The DV was significantly lower in the cocaine cue than in the neutral condition in the putamen $(p<0.05)$ and showed a trend in the caudate $(p<0.06)$ but did not differ in ventral striatum or in cerebellum (Table 2). SPM analysis corroborated the significant DV reduction in dorsal (caudate and putamen) but not in ventral striatum (Fig. 1).

Table 2. $K_{1}$ (transport constant from plasma to tissue) and DV measures for the neutral and the cocaine-cue video conditions and $t$ and $p$ values for their comparisons (paired two-tail $t$ test)

\begin{tabular}{lllll}
\hline & Neutral video & Cocaine-cue video & $t$ & $p$ \\
\hline$K_{1}$ & & & & \\
$\quad$ Cerebellum & $0.12 \pm 0.03$ & $0.11 \pm 0.04$ & 0.33 & 0.75 \\
$\quad$ Caudate & $0.10 \pm 0.01$ & $0.11 \pm 0.04$ & 0.93 & 0.37 \\
Putamen & $0.11 \pm 0.02$ & $0.12 \pm 0.04$ & 1.00 & 0.33 \\
$\quad$ Ventral striatum & $0.10 \pm 0.01$ & $0.11 \pm 0.03$ & 0.60 & 0.55 \\
DV & & & \\
$\quad$ Cerebellum & $0.43 \pm 0.06$ & $0.43 \pm 0.06$ & 0.44 & 0.67 \\
Caudate & $1.44 \pm 0.20$ & $1.37 \pm 0.24$ & 2.02 & 0.06 \\
Putamen & $1.62 \pm 0.22$ & $1.53 \pm 0.26$ & 2.08 & 0.05 \\
Ventral striatum & $1.46 \pm 0.26$ & $1.42 \pm 0.22$ & 0.59 & 0.56 \\
\hline
\end{tabular}

DV measures in putamen were significantly lower $(p<0.05)$ during the cocaine-cue condition and showed a trend in caudate $(p<0.06)$. None of the othe measures differed. Values represent means $\pm S D$ s. 


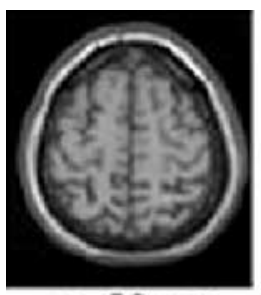

$\mathrm{z}=20 \mathrm{~mm}$

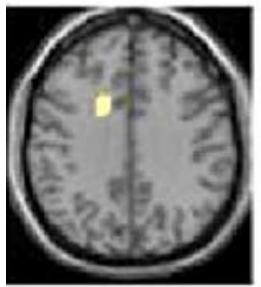

$z=36 \mathrm{~mm}$

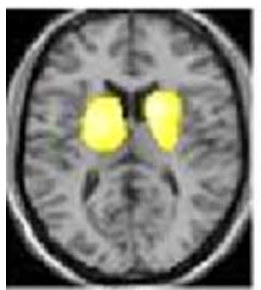

$z=12 \mathrm{~mm}$

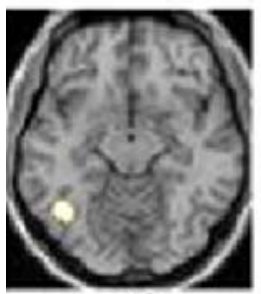

$z=-12 \mathrm{~mm}$

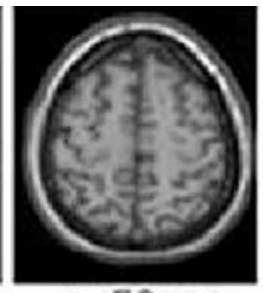

$z=56 \mathrm{~mm}$

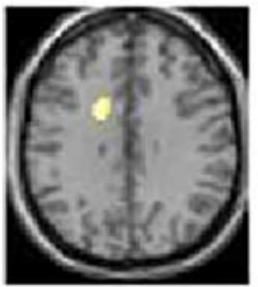

$z=32 \mathrm{~mm}$



$z=8 \mathrm{~mm}$

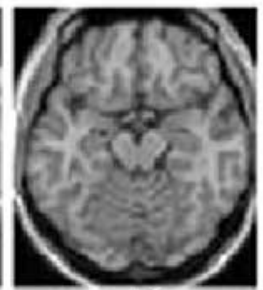

$z=-16 \mathrm{~mm}$

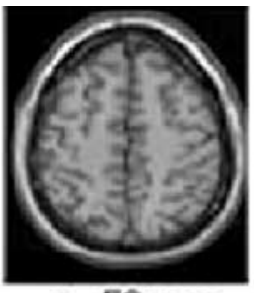

$z=52 \mathrm{~mm}$



$z=28 \mathrm{~mm}$

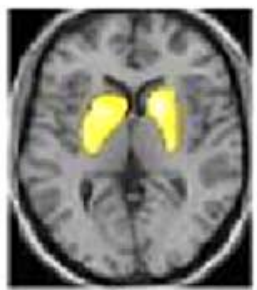

$z=4 \mathrm{~mm}$

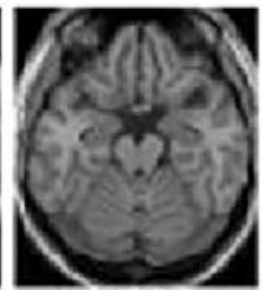

$z=-20 \mathrm{~mm}$



$\mathrm{z}=48 \mathrm{~mm}$

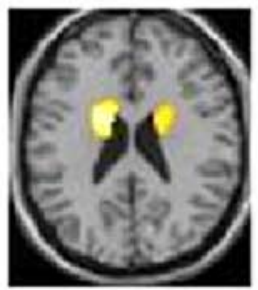

$\mathrm{z}=24 \mathrm{~mm}$

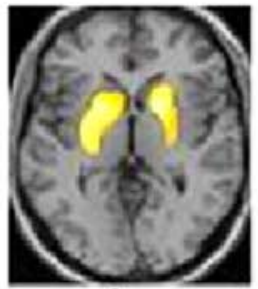

$\mathrm{z}=0 \mathrm{~mm}$

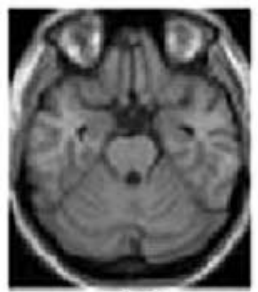

$z=-24 \mathrm{~mm}$



$\mathrm{z}=44 \mathrm{~mm}$

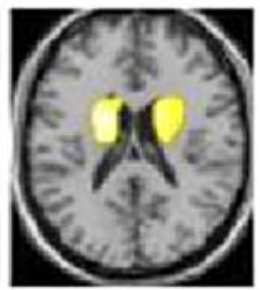

$z=20 \mathrm{~mm}$

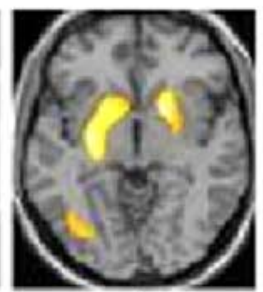

$z=-4 \mathrm{~mm}$

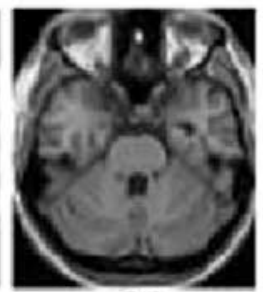

$z=-28 \mathrm{~mm}$

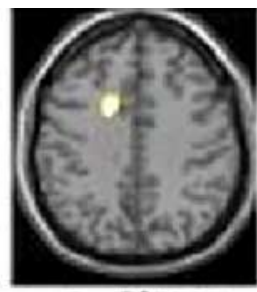

$\mathrm{z}=40 \mathrm{~mm}$

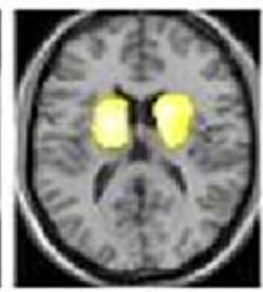

$\mathrm{z}=16 \mathrm{~mm}$



$z=-8 \mathrm{~mm}$



$z=32 \mathrm{~mm}$

Figure 1. Brain maps obtained with SPM showing the difference in the distribution volume of $\left[{ }^{11} \mathrm{C}\right]$ raclopride between the neutral and the cocaine-cue conditions ( $p<0.05$, uncorrected, threshold $>100$ voxels). Note that there were no differences in the ventral striatum ( -8 canthomeatal plane).

The Bmax/Kd measures, which reflect $\mathrm{D}_{2}$ receptors that are not occupied by endogenous DA, were significantly lower in the cocaine cue than in the neutral condition in caudate $(t=2.3 ; p<$ $0.05)$ and in putamen $(t=2.2 ; p<0.05)$ but did not differ in ventral striatum $(t=0.37 ; p=0.71)$ (Fig. $2 A)$. This indicates that cocaine cues induced DA release in the dorsal striatum.

\section{Effects of cocaine cues on craving and correlation with} behavioral measures

The cocaine-cue video significantly increased the craving scores (CCQ) from $2.9 \pm 1.4$ to $3.5 \pm 1.4(t=2.9 ; p<0.01)$, whereas the neutral video did not; scores before the video were $2.8 \pm 1.6$ and after the video were $3.0 \pm 1.7(t=1.1 ; p<0.30)$ (Fig. $2 B)$. The correlations between the changes in craving and the DA changes did not differ for left and right regions and thus we report on the correlations for the average measures. These correlations were significant in putamen $(r=0.69 ; p<0.002)$ and in caudate $(r=$ $0.54 ; p=0.03)$ but not in ventral striatum $(r=0.36 ; p=0.14)$ (Fig. 2C).

Correlation analysis between the DA changes and the clinical scales revealed a significant association between the CSSA and the DA changes in caudate $(r=0.55 ; p<0.01)$ and a trend in putamen $(r=0.40 ; p=0.10)$. Similarly, the scores on the ASI were significantly correlated with DA changes in right putamen $(r=$ $0.47 ; p<0.05)$, left and right ventral striatum $(r=0.50 ;<0.04)$, and a trend in left caudate $(r=0.41 ; p=0.09)$. The greater the severity on the CSSA and the ASI the larger the DA changes.

The correlation between the measures of $\mathrm{D}_{2}$ receptor availability obtained during the neutral video and the clinical scales (CCQ, CSSA, and ASI) were not significant.

\section{Discussion}

Effects of cocaine cues on DA in striatum

Here we show increases in DA in the dorsal striatum in cocaineaddicted subjects watching a video that showed cocaine cues. These results are in agreement with microdialysis studies documenting increases in extracellular DA in the dorsal striatum in rodents responding to cocaine cues (Ito et al., 2002). However, the microdialysis studies reported DA increases in dorsal striatum only when the cocaine cues were presented contingently (Ito 


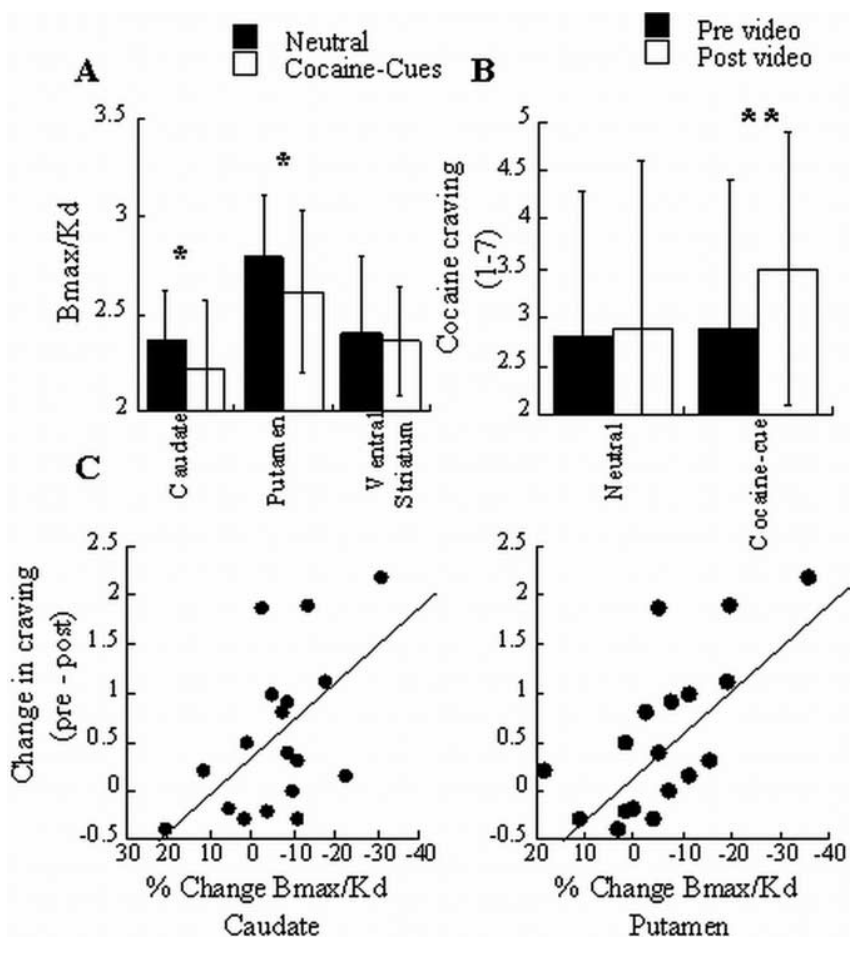

Figure 2. $\quad A$, Dopamine $\mathrm{D}_{2}$ receptor availability (Bmax/Kd) in caudate, putamen, and ventral striatum for the neutral and the cocaine-cue conditions. $\boldsymbol{B}$, Craving measures (assessed with the CCQ) before (pre) and after (post) presentation of the neutral and the cocaine videos. C, Regression slopes for the correlation between changes in DA (percentage changes in Bmax/Kd from the neutral condition) and changes in cocaine craving (pre and post differences in $C(Q$ scores). Values represent means $\pm S D$ s. Comparisons correspond to paired $t$ tests (two-tailed) ${ }^{*} p<$ $0.05 ;{ }^{* *} p<0.01$.

et al., 2002), whereas noncontingent presentation increased DA instead in the NAc (Neisewander et al., 1996). In our study, the cocaine cues were noncontingent because the subjects were not required to emit any responses to watch the video, yet the cocaine cues elicited significant DA increases in dorsal striatum and not in ventral striatum (in which NAc is located). This is likely to reflect differences between preclinical and clinical paradigms; specifically, rodents are trained that responding to the cues predicts drug delivery, whereas for the cocaine-addicted subjects, exposure to scenes with "cocaine cues" does not predict drug delivery but instead primes them to engage in the behaviors required to procure the drug. That is, the delivery of cocaine will not occur automatically but, as would be the case for contingent presentation in rodents, requires the emission of behaviors. Thus, DA activation of the dorsal striatum by cocaine cues appears to occur when behavioral responses are necessary to procure the drug as opposed to cocaine cues that predict drug delivery regardless of the behavioral response emitted (Vanderschuren et al., 2005). This is consistent with the role of the dorsal striatum in the selection and initiation of actions (Graybiel et al., 1994).

\section{Dopamine in dorsal striatum and craving}

In this study, we show an association between cocaine craving and DA increases in dorsal striatum (caudate and putamen). Because the main projection from DA cells to dorsal striatum arises from the substantia nigra (Haber and Fudge, 1997), this implicates the DA nigrostriatal pathway in the subjective experience of craving. This is consistent with previous imaging studies showing that activation of the putamen in cocaine abusers was associated with craving induced by intravenous cocaine as assessed by blood oxygenation level-dependent (BOLD) changes with functional magnetic resonance imaging (fMRI) [negative association (Breiter et al., 1997) as well as positive association (Risinger et al., 2005)] or by intravenous methylphenidate administration as assessed by changes in brain glucose metabolism with PET [positive association (Volkow et al., 1999)]. Craving triggered by stress in cocaine abusers was also associated with activation of the dorsal striatum (including caudate) as assessed with fMRI (Sinha et al., 2005). Similarly, an fMRI study that compared responses between a neutral and a cocaine video related the enhanced BOLD signaling in dorsal striatum during the cocaine video to the craving induced by the video (Garavan et al., 2000).

The dorsal striatum is involved with the selection and initiation of actions (Graybiel et al., 1994), and recent studies now implicate it in mediating stimulus-response (habit) learning, including that which occurs with chronic drug administration (White and McDonald, 2002). Thus, the association between dorsal striatal dopaminergic activity and cue-induced cocaine craving could reflect the habit-based (automatized) nature of craving in addiction (Tiffany, 1990). Several preclinical and clinical studies have documented involvement of the dorsal striatum with chronic exposure to cocaine (Letchworth et al., 2001; Porrino et al., 2004; Volkow et al., 2004). In fact, in laboratory animals, the dorsal regions of the striatum become progressively more engaged by cocaine as chronicity progresses (Letchworth et al., 2001; Porrino et al., 2004). Indeed, it is hypothesized that the dorsal striatum mediates the habitual nature of compulsive drug seeking in cocaine addiction (Tiffany, 1990; Robbins and Everitt, 1999).

DA is involved in the regulation of motivation and reward (or prediction of reward) (Wise and Rompre, 1989; Schultz et al., 1997). In the current study, the exposure to the cocaine video was a strong "reward predictor" (by its long conditioning history), but subjects in the study were aware that drug reward (actual cocaine) would not be available. In this respect, these findings are similar to those in studies of healthy subjects shown food cues that they could not consume, which documented DA increases in the dorsal striatum that were associated with the "desire for the food." Although the DA increases were smaller after exposure to food stimuli than after exposure to cocaine cues, the direction of the correlation was similar: the greater the DA increases, the greater the desire (Volkow et al., 2002). It would appear as if DA activation of dorsal striatum is involved with the "desire" (wanting), which would result in the readiness to engage in the behaviors necessary to procure the desired object. These parallel findings suggest the intriguing hypothesis that in the human brain, drug addiction may engage the same neurobiological processes that motivate behaviors required for survival that are triggered by food-conditioned cues.

\section{Reactivity of the striatum and addiction severity}

The cue-elicited DA changes were also associated with estimates of severity of addiction (assessed with ASI and CSSA); the greater the addiction severity, the larger the DA increases. Because the dorsal striatum is implicated in habit learning, this association could reflect the strengthening of habits as chronicity progresses. Because the CSSA is a measure that has been shown to predict treatment outcomes in cocaine-addicted subjects (Kampman et al., 2002), this suggests that the reactivity of the DA system to drug cues may be a biomarker for negative outcomes in cocaineaddicted subjects. It also suggests that basic neurobiological disruptions in addiction are the conditioned neurobiological responses that result in activation of DA pathways that trigger the 
behavioral habits leading to compulsive drug seeking and consumption. It is likely that these conditioned neurobiological responses reflect corticostriatal and corticomesencephalic glutamatergic adaptations (Kalivas and Volkow, 2005).

\section{Nucleus accumbens and craving}

This study did not find an association between craving and DA changes in ventral striatum (in which the NAc is located). This was unexpected because studies in laboratory animals have shown that the NAc is part of the neural circuitry that mediates cue-induced relapse to cocaine seeking (Fuchs et al., 2004). This could imply that the involvement of the NAc in craving is nondopaminergic. Indeed, glutamatergic projections into the NAc have been directly implicated in cue-associated drug-seeking behavior, which is an effect that is not blocked by DA antagonists (Di Ciano and Everitt, 2004). However, some investigators (Gratton and Wise, 1994; Kiyatkin and Stein, 1996; Duvauchelle et al., 2000; Ito et al., 2000; Weiss et al., 2000), although not all (Brown and Fibiger, 1992; Bradberry et al., 2000), have shown DA increases in NAc with presentation of cocaine cues. As discussed, this could reflect the conditions under which the cues were presented (contingent vs noncontingent). Also, the stimuli in the preclinical studies serve a different function from those in the current study; because they signal the availability of cocaine, they act as a discriminative stimulus, whereas if they are paired or associated with cocaine presentation (as the cues were in the present study), they are conditioned stimuli. However, they could also reflect differences in species (humans vs rodents), experimental paradigms (videos showing cues vs physical presence of cues), and methods for measuring DA (PET vs microdialysis and voltammetry).

\section{Study limitations}

The limited spatial resolution of the PET methodology constrained us to measure ventral striatum rather than NAc. Also, its relatively poor temporal resolution allowed us to detect DA changes over a 20-30 min period, limiting our ability to detect short-lasting DA increases as reported for cocaine cues with voltammetry (Phillips et al., 2003). In addition, the $\left[{ }^{11} \mathrm{C}\right]$ raclopride method is best suited to detect DA release in regions of high $\mathrm{D}_{2}$ receptor density such as striatum, but not low receptor density such as extrastriatal regions, which could explain why we did not show DA changes in amygdala, in which animals studies have shown cue-elicited DA increases (Weiss et al., 2000).

Although we show that the variability in the magnitude of the DA changes induced by the cocaine cue is associated with the severity of the addiction process, it could also reflect differences in reactivity of DA cells that may have preceded the abuse of substances. In this study, 17 of the 18 subjects were males and thus future studies are needed to examine gender differences.

\section{Conclusions}

Because the DA increases in dorsal striatum elicited by drug cues predicted addiction severity, this provides evidence of a fundamental involvement of the nigrostriatal DA pathway in craving and in cocaine addiction in humans. It also suggests that compounds that could inhibit cue-induced striatal DA increases would be logical targets for the development of pharmacological interventions to treat cocaine addiction.

Note added in proof. Similar findings of increases in dopamine in the dorsal striatum during cocaine craving were reported as preliminary data by Wong et al. (2003).

\section{References}

Bradberry CW, Barrett-Larimore RL, Jatlow P, Rubino SR (2000) Impact of self-administered cocaine and cocaine cues on extracellular dopamine in mesolimbic and sensorimotor striatum in rhesus monkeys. J Neurosci 20:3874-3883.

Breier A, Su TP, Saunders R, Carson RE, Kolachana BS, de Bartolomeis A, Weinberger DR, Weisenfeld N, Malhotra AK, Eckelman WC, Pickar D (1997) Schizophrenia is associated with elevated amphetamine-induced synaptic dopamine concentrations: evidence from a novel positron emission tomography method. Proc Natl Acad Sci USA 94:2569-2574.

Breiter HC, Gollub RL, Weisskoff RM, Kennedy DN, Makris N, Berke JD, Goodman JM, Kantor HL, Gastfriend DR, Riorden JP, Mathew RT, Rosen BR, Hyman SE (1997) Acute effects of cocaine on human brain activity and emotion. Neuron 19:591-611.

Brown EE, Fibiger HC (1992) Cocaine-induced conditioned locomotion: absence of associated increases in dopamine release. Neuroscience 48:621-629.

Childress AR, Mozley PD, McElgin W, Fitzgerald J, Reivich M, O’Brien CP (1999) Limbic activation during cue-induced cocaine craving. Am J Psychiatry 156:11-18.

Childress AR, Franklin T, Listerud J, Acton P, O’Brien CP (2002) Neuroimaging of cocaine craving states: cessation, stimulant administration and drug cue paradigms. In: Neuropsychopharmacology: a fifth generation of progress (Davis KL, Charney D, Coyle JT, Nemeroft C, eds), pp 15751590. Philadelphia: Lippincott Williams \& Wilkins.

Di Chiara G, Imperato A (1988) Drugs abused by humans preferentially increase synaptic dopamine concentrations in the mesolimbic system of freely moving rats. Proc Natl Acad Sci USA 85:5274-5278.

Di Ciano P, Everitt BJ (2004) Direct interactions between the basolateral amygdala and nucleus accumbens core underlie cocaine-seeking behavior by rats. J Neurosci 24:7167-7173.

Duvauchelle CL, Ikegami A, Castaneda E (2000) Conditioned increases in behavioral activity and accumbens dopamine levels produced by intravenous cocaine. Behav Neurosci 114:1156-1166.

Friston KJ, Holmes AP, Worsley KJ, Poline JB, Frith CD, Frackowiak RSJ (1995) Statistical parametric maps in functional imaging: a general linear approach. Hum Brain Mapp 2:189-210.

Fuchs RA, Evans KA, Parker MP, See RE (2004) Differential involvement of orbitofrontal cortex subregions in conditioned cue-induced and cocaineprimed reinstatement of cocaine seeking in rats. J Neurosci 24:6600-6610.

Garavan H, Pankiewicz J, Bloom A, Cho JK, Sperry L, Ross TJ, Salmeron BJ, Risinger R, Kelley D, Stein EA (2000) Cue-induced cocaine craving: neuroanatomical specificity for drug users and drug stimuli. Am J Psychiatry 157:1789-1798.

Gratton A, Wise RA (1994) Drug- and behavior-associated changes in dopamine-related electrochemical signals during intravenous cocaine self-administration in rats. J Neurosci 14:4130-4146.

Graybiel AM, Aosaki T, Flaherty AW, Kimura M (1994) The basal ganglia and adaptive motor control. Science 265:1826-1831.

Haber SN, Fudge JL (1997) The primate substantia nigra and VTA: integrative circuitry and function. Crit Rev Neurobiol 11:323-342.

Ito R, Dalley JW, Howes SR, Robbins TW, Everitt BJ (2000) Dissociation in conditioned dopamine release in the nucleus accumbens core and shell in response to cocaine cues and during cocaine-seeking behavior in rats. J Neurosci 20:7489-7495.

Ito R, Dalley JW, Robbins TW, Everitt BJ (2002) Dopamine release in the dorsal striatum during cocaine-seeking behavior under the control of a drug-associated cue. J Neurosci 22:6247-6253.

Kalivas PW, Volkow ND (2005) The neural basis of addiction: a pathology of motivation and choice. Am J Psychiatry 162:1403-1413.

Kampman KM, Volpicelli JR, McGinnis DE, Alterman AI, Weinrieb RM, D’Angelo L, Epperson LE (1998) Reliability and validity of the Cocaine Selective Severity Assessment. Addict Behav 23:449-461.

Kampman KM, Volpicelli JR, Mulvaney F, Rukstalis M, Alterman AI, Pettinati H, Weinrieb RM, O’Brien CP (2002) Cocaine withdrawal severity and urine toxicology results from treatment entry predict outcome in medication trials for cocaine dependence. Addict Behav 27:251-260.

Kiyatkin EA, Stein EA (1996) Conditioned changes in nucleus accumbens dopamine signal established by intravenous cocaine in rats. Neurosci Lett 211:73-76.

Koob GF, Bloom FE (1988) Cellular and molecular mechanisms of drug dependence. Science 242:715-723. 
Letchworth SR, Nader MA, Smith HR, Friedman DP, Porrino LJ (2001) Progression of changes in dopamine transporter binding site density as a result of cocaine self-administration in rhesus monkeys. J Neurosci 21:2799-2807.

Logan J, Fowler JS, Volkow ND, Wolf AP, Dewey SL, Schlyer DJ, MacGregor RR, Hitzemann R, Bendriem B, Gatley SJ (1990) Graphical analysis of reversible radioligand binding from time-activity measurements applied to [N-11C-methyl]-(-)-cocaine PET studies in human subjects. J Cereb Blood Flow Metab 10:740-747.

Logan J, Volkow ND, Fowler JS, Wang GJ, Dewey SL, MacGregor R, Schlyer D, Gatley SJ, Pappas N, King P (1994) Effects of blood flow on [11C]raclopride binding in the brain: model simulations and kinetic analysis of PET data. J Cereb Blood Flow Metab 14:995-1010.

McLellan AT, Kushner H, Metzger D, Peters R, Smith I, Grissom G, Pettinati H, Argeriou M (1992) The fifth edition of the Addiction Severity Index. J Subst Abuse Treat 9:199-213.

Neisewander JL, O’Dell LE, Tran-Nguyen LT, Castaneda E, Fuchs RA (1996) Dopamine overflow in the nucleus accumbens during extinction and reinstatement of cocaine self-administration behavior. Neuropsychopharmacology 15:506-514.

O’Brien CP, Childress AR, Ehrman R, Robbins SJ (1998) Conditioning factors in drug abuse: can they explain compulsion? J Psychopharmacol 12:15-22.

Phillips PE, Stuber GD, Heien ML, Wightman RM, Carelli RM (2003) Subsecond dopamine release promotes cocaine seeking. Nature 422:614-618.

Porrino LJ, Lyons D, Smith HR, Daunais JB, Nader MA (2004) Cocaine self-administration produces a progressive involvement of limbic, association, and sensorimotor striatal domains. J Neurosci 24:3554-3562.

Risinger RC, Salmeron BJ, Ross TJ, Amen SL, Sanfilipo M, Hoffmann RG, Bloom AS, Garavan H, Stein EA (2005) Neural correlates of high and craving during cocaine self-administration using BOLD fMRI. NeuroImage 26:1097-1108.

Robbins TW, Everitt BJ (1999) Drug addiction: bad habits add up. Nature 398:567-570.

Schultz W, Dayan P, Montague PR (1997) A neural substrate of prediction and reward. Science 275:1593-1599.

Sinha R, Lacadie C, Skudlarski P, Fulbright RK, Rounsaville BJ, Kosten TR, Wexler BE (2005) Neural activity associated with stress-induced cocaine craving: a functional magnetic resonance imaging study. Psychopharmacology (Berl) 183:171-180.

Tiffany ST (1990) A cognitive model of drug urges and drug-use behavior: role of automatic and nonautomatic processes. Psychol Rev 97:147-168.

Tiffany ST, Singleton E, Haertzen CA, Henningfield JE (1993) The development of a cocaine craving questionnaire. Drug Alcohol Depend 34:19-28.

Vanderschuren LJ, Di Ciano P, Everitt BJ (2005) Involvement of the dorsa striatum in cue-controlled cocaine seeking. J Neurosci 25:8665-8670.

Volkow ND, Fowler JS, Wang GJ, Dewey SL, Schlyer D, MacGregor R, Logan J, Alexoff D, Shea C, Hitzemann R, et al (1993) Reproducibility of repeated measures of carbon-11-raclopride binding in the human brain. J Nucl Med 34:609-613.

Volkow ND, Wang GJ, Fowler JS, Logan J, Schlyer D, Hitzemann R, Lieberman J, Angrist B, Pappas N, MacGregor R (1994) Imaging endogenous dopamine competition with [11C]raclopride in the human brain. Synapse 16:255-262.

Volkow ND, Wang GJ, Fowler JS, Hitzemann R, Angrist B, Gatley SJ, Logan J, Ding YS, Pappas N (1999) Association of methylphenidate-induced craving with changes in right striato-orbitofrontal metabolism in cocaine abusers: implications in addiction. Am J Psychiatry 156:19-26.

Volkow ND, Wang GJ, Fowler JS, Logan J, Jayne M, Franceschi D, Wong C, Gatley SJ, Gifford AN, Ding YS, Pappas N (2002) "Nonhedonic" food motivation in humans involves dopamine in the dorsal striatum and methylphenidate amplifies this effect. Synapse 44:175-180.

Volkow ND, Fowler JS, Wang GJ, Swanson JM (2004) Dopamine in drug abuse and addiction: results from imaging studies and treatment implications. Mol Psychiatry 9:557-569.

Weiss F, Maldonado-Vlaar CS, Parsons LH, Kerr TM, Smith DL, Ben-Shahar O (2000) Control of cocaine-seeking behavior by drug-associated stimuli in rats: effects on recovery of extinguished operant-responding and extracellular dopamine levels in amygdala and nucleus accumbens. Proc Natl Acad Sci USA 97:4321-4326.

White NM, McDonald RJ (2002) Multiple parallel memory systems in the brain of the rat. Neurobiol Learn Mem 77:125-184.

Wise RA, Rompre PP (1989) Brain dopamine and reward. Annu Rev Psychol 40:191-225.

Wong DF, Lee JS, Maini A, Zhou Y, Kuwabara H, Endres C, Brasic J, Dogan AS, Schretlen D, Alexander M, Kimes E, Ernst M, Jasinski D, London ED Zukin S (2003) Cue induced cocaine craving and dopamine release: methodology and correlates. J Nucl Med 44:67. 